\title{
THE WASTE CLUSTER INITIATIVE - EVOLVING FROM A CLUSTER OF PROJECTS TO A CLUSTER OF KNOWLEDGE
}

\author{
Helder Rosendo \\ CITEVE - Textile Technology Centre of Portugal
}

\begin{abstract}
The WASTE CLUSTER INITIATIVE (WCI) focuses on the creation of an international balanced network of (regional) waste management-related initiatives, for mutual learning and exchange of knowledge, skills and technologies that will lead to an optimization of waste management-related innovation and competitiveness excellence. This cluster will stimulate the innovation and business creation by the expansion and enhancement of a network of regional waste management-oriented clusters, not only circumscribed at a European dimension but also considering Mediterranean Partner Countries MPCs, thus maximizing the usage of knowledge spillovers. This cluster involves the spatial concentration of complementary activities with intensive interaction, achieving extraordinary performance and competitiveness, obtaining benefits for industry, society and research. WASTE CLUSTER takes advantage starting form a natural integration of different ongoing projects such as SOWAEUMED, STInno, WASTEKIT and TEMP, which had already identify two strategic common topics that should be the major thematic focus of the WASTE CLUSTER INITIATIVE: 1)Water and Waste Water management \& 2) Waste into Products Technologies and Processes. WASTE CLUSTER is a free entrance strategy rather than a close club, where the diffusion to all the Project partners is ensured in order to reinforce their diffusion to their regional potential interested stakeholders and try to obtain funding synergies. The cluster should be connected to the Water Supply and Sanitation Technology Platform (WSSTP) in order to build a common agenda.
\end{abstract}

\section{KEYWORDS}

Clustering - Waste Management - Water Management- Research and Knowledge Exchange

https://doi.org/10.15626/Eco-Tech.2010.074 


\section{INTRODUCTION}

The WASTE CLUSTER INTIATIVE is a genuine 'research-driven' cluster of cooperating regions with a strong emphasis on exchange of best practices and knowledge transfer. In the beginning of 2010, the WASTE-CLUSTER initiative was launched with the ambition of involving different European Community funded research projects in an exchange of knowledge and experiences, learning from each other's strengths and weaknesses, defining regional strategies and investing in strengths through integral use of national and regional funding. Due to the involvement of partners from the Mediterranean Partner Countries (MPCs), the cluster's main target is knowledge transfer to directly enhance visibility of the MPCs in the cluster and prepare the grounds for their integration into the European Research Area (ERA). At this stage the WCI hás define a roadmap and a common agenda for those projects and initiatives working in the field of Waste management, with particular emphasis on the issue of Smart Water Management.

\section{HE ROADMAP OF THE WASTE CLUSTER INITIATIVE}

Each year in the European Union alone we throw away 3 billion tonnes of waste - some 90 million tonnes of it hazardous. This amounts to about 6 tonnes of solid waste for every man, woman and child, according to Eurostat statistics. It is clear that treating and disposing of all this material - without harming the environment - becomes a major headache. Between 1990 and 1995, the amount of waste generated in Europe increased by $10 \%$, according to the Organization for Economic Cooperation and Development (OECD). Most of what we throw away is either burnt in incinerators, or dumped into landfill sites (67\%). But both these methods create environmental damage. Landfilling not only takes up more and more valuable land space, it also causes air, water and soil pollution, discharging carbon dioxide (CO2) and methane (CH4) into the atmosphere and chemicals and pesticides into the earth and groundwater. This, in turn, is harmful to human health, as well as to plants and animals. In the EU, the amount of residual waste available for energy recovery can supply approximately $1 \%$ of the primary energy demand. On the other side, The EU is aiming for a significant cut in the amount of rubbish generated, through new waste prevention initiatives, better use of resources, and encouraging a shift to more sustainable consumption patterns. The European Union's approach to waste management is based on three principles: 1) Prevention, 2) Recycling \& Reuse and 3) Improving final disposal and monitoring Not less important, is the particular influence of smart water and waste management practices in the competitiveness of most industrial processes, namely those of strategic importance for the EU-MED region like textiles \& clothing or olive oil production. Smart waste management, particularly water and waste water management, have become not only an important way for costs reduction, but also an important marketing and communication asset, when it comes to addressing educated and well informed consumers.

In that sense the short term roadmap that was jointly defined by the $4 \mathrm{EU}$ funded projects SOWAEUMED, STInno, WASTEKIT and TEMP, tries to address not only the particular problems which are in the essence of those projects, but also, the major EU challenges regarding waste management. 
Linnaeus ECO-TECH '10

Kalmar, Sweden, November 22-24, 2010

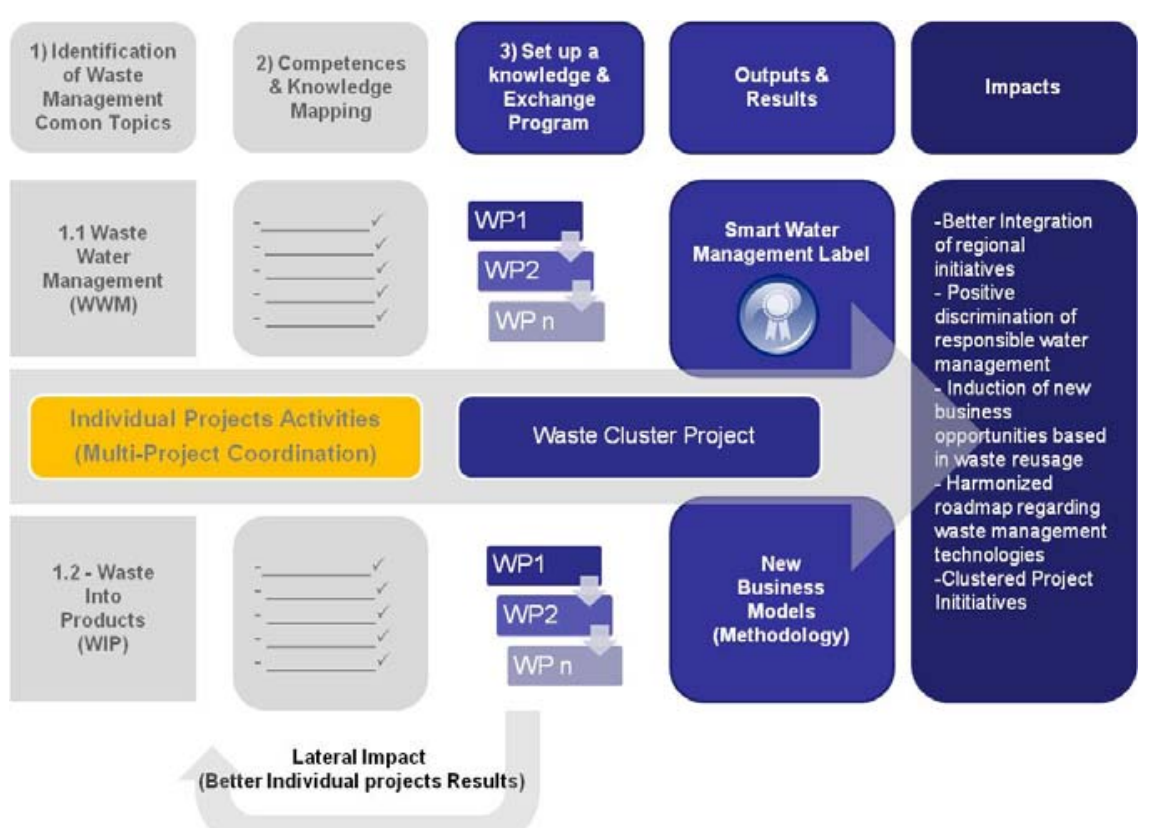

Figure 1 - Roadmap of the Waste Cluster Initiative The design of such a roadmap was also based on a SWAT exercise, aiming the identification of the strengths and opportunities for the implementation of such a strategy.

\begin{tabular}{|c|c|c|c|}
\hline \multicolumn{2}{|r|}{ Strengths } & \multicolumn{2}{|r|}{ Opportunities } \\
\hline S1 & $\begin{array}{l}\text { Infrastructure for solid waste- and } \\
\text { wastewater characterisation (chemical, } \\
\text { biological, ... characteristics) }\end{array}$ & 01 & $\begin{array}{l}\text { Available databases of projects, results, } \\
\text { technology available }\end{array}$ \\
\hline S2 & $\begin{array}{l}\text { Know-how among the researchers, } \\
\text { helicopter view }\end{array}$ & $\mathrm{O} 2$ & $\begin{array}{l}\text { Awareness in society about waste } \\
\text { problems }\end{array}$ \\
\hline S3 & Strong in protecting ground water & O3 & Funding opportunities in the EU \\
\hline S4 & $\begin{array}{l}\text { Openess towards collaboration, initiatives, } \\
\text { idease }\end{array}$ & O4 & Availibility of valorisation technologies \\
\hline S5 & Infrastructure for waste treatment & 05 & Entrepreneurial potential to do business \\
\hline \multicolumn{2}{|r|}{ Weaknesses } & \multicolumn{2}{|r|}{ Threats } \\
\hline w1 & Lack of knowledge transfer & T1 & $\begin{array}{l}\text { No broad strategy for technology } \\
\text { transfer and innovation }\end{array}$ \\
\hline w2 & Lack of business development & $\mathrm{T} 2$ & Competition with China \\
\hline w3 & Poor IP management & T3 & $\begin{array}{l}\text { Slow reaction of public policy and } \\
\text { regulation on research findings }\end{array}$ \\
\hline w4 & $\begin{array}{l}\text { No representation of business in } \\
\text { universities }\end{array}$ & T4 & $\begin{array}{l}\text { Different oriëntation of business } \\
\text { community }\end{array}$ \\
\hline w5 & No research performance indicators & T5 & Political short term thinking \\
\hline
\end{tabular}

Figure 2 - SWAT analysis result 


\section{RESULTS AND DISCUSSION}

The implementation of the Waste Cluster Initiative is expected to achieve different kind of results at different scales, with different degrees of applicability and with different impacts:

Besides all the relevant impacts and outputs described in figure 1 and which are normally associated to any cluster activity there are two concrete outputs which should be very briefly described and highlighted:

\subsection{The Smart Water Management Approach/The MULTIWATER Proposal}

The objective is to define a sort of a best practice guide book regarding water management in different industrial activities, promoting smart water management procedures, technologies and processes, associated to an audit and a certification standard that can lead to a certificate guaranteed and issued by the WCI. This would be a voluntary certification EUMED system aiming to award those companies and organizations following best practices in terms of water and waste water management. The label to be used by the certificated companies should work as a positive discrimination in the market for those applying smart water and waste water management practices. The expertise already available in the WCI and the strong regional dimension the could be ensured from the very beginning, makes that label a powerful instrument to promote and to improve environmental responsibility at water management level within the EUMED area. In this particular field, a fisrt common proposal is already in the pipe line aiming to support part of this development, and has been by the acronym MULTIWATER.

\subsection{New business Models for Waste Into Product Strategies}

In several cases the huge market potential of products made upon waste resulting from a variety of different industrial processes is lost or does not reach the expected promising dimension. In most cases, even having good proof of concept for an innovative product and having good performance and aesthetic properties, is not enough to achieve a successful business story. One of the major reasons for that failure rate is the fact that building a business plan for an innovative product made (mostly) of waste, does not have exactly the same constrains that a normal business plan. The idea is to develop a methodology that can contribute to the reduction of the mortality rate of innovative business ideas resulting from transforming waste into products or into business itself, helping to promote and bringing into life a more significant number of business cases build upon waste resulting from different industrial sectors.

Not less important are the global and strategic impacts that can be expected from such clustered initiative:

- Better integration of local and regional policies and regulations regarding water and waste management;

- Regional recognition of good water and waste management practices, promoting a positive discrimination of companies and business agents applying smart waste management approaches that will induce to a better regional environmental industrial performance;

- Promotion of reusing and recycling as a way for new business development, contributing to the generation of sustainable high qualified new jobs and new business opportunities; 
- More effective and smarter resource allocation regarding project supporting programs, resulting from a more intensive and clustered knowledge management approach, the reduces the possibility of overlapping between national, regional and European initiatives.

- Better regional and national research \& innovation strategies, resulting from a clustered road mapping activity

\section{CONCLUSIONS}

So far, the WCI has been living trough a voluntary basis and upon very limited resources, allocated in the dissemination activities budget from the four projects that had started to share this vision on a common kick of meeting, held in January 2010. This stage is identified in figure 1, namely on activities 1 (Identification of strategic common topics) and 2 (competence and knowledge mapping) presented in grey color. In fact, it has become clear to every organization involved in this cooperation process, that bringing to life a real cluster, can't be done using such a limited pack of resources. What the partners involved have being doing until now, which is indeed quite relevant and useful, is to promote the share of knowledge and ideas between the four consortia, namely to avoid overlapping of efforts and activities and to promote a better cross linked approach between the 4 ongoing projects. This is more or less an integrated multi-project coordination activity regarding the four parallel workprogrames. Therefore, to evolve from a coordination activity that is more likely a cluster of projects, to a real cluster of regions and initiatives, focused on the Waste Management and with a stronger impact at regional scale, a new project should be design, targeting the identified outputs and strategies. This new dimension should probably bring together not only the partners involved in the WCI, but also other key players, identified as relevant to implement on a wider scale the objectives and challenges defined in the present roadmap of the WCI.

\section{ACKNOWLEDGEMENTS}

To all the coordinators of the 3 other WCI projects: Ilse Van Den Breemer, coordinator of the WASTEKIT project, Johanna Kilpi-Koski, coordinator of the STInno Project and.Manuel Valiente, Coordinator of the SOWAEUMED Project

\section{REFERENCES}

[1]@European Union waste management strategy and the importance of biogenic waste, Juergen Vehlow, Britta Bergfeldt, Rian Visser and Carl Wilén, 26 September 2007, @ Springer

[2]@http://ec.europa.eu/environment/enlarg/med/index.htm

[3] @http://ec.europa.eu/environment/waste/index.htm 